\title{
Development of nanotechnology in andrology
}

\author{
Sheng-Zhuo Liu", De-Chao Feng", Zhi-Hong Liu, Jia-Yu Liang, Zheng-Ju Ren, Chuan Zhou, Kan Wu, \\ Fu-Xun Zhang, Fan Zhang, Yi-Ping Lu, Xian-Ding Wang
}

Department of Urology/Institute of Urology, West China Hospital, Sichuan University, Chengdu 610041, China

Contributions: (I) Conception and design: SZ Liu, DC Feng, YP Lu, XD Wang; (II) Administrative support: XD Wang; (III) Provision of study materials or patients: SZ Liu, DC Feng; (IV) Collection and assembly of data: SZ Liu, DC Feng; (V) Data analysis and interpretation: SZ Liu, DC Feng; (VI) Manuscript writing: All authors; (VII) Final approval of manuscript: All authors.

\#These authors contributed equally to this work.

Correspondence to: Yi-Ping Lu; Xian-Ding Wang. Professor, Department of Urology/Institute of Urology, West China Hospital, Sichuan University, Guoxuexiang 37, Chengdu 610041, China. Email: luyiping_wch@126.com; xiandingwang@outlook.com.

\begin{abstract}
Since first introduced in 1980s, nanotechnology has always been the eye-catching point as its providing us with new approaches to explore the microscopic world. Many nanotechnology-associated novel technologies have been brought into clinical use in the past decades and uncountable patients benefited from them, which convinces us of a bright prospect of nanotechnology in the field of medicine. In this review, literatures concerning nanotechnology applications in andrology were retrieved and we made a comprehensive discussion on drug delivery, gene therapy and stem cell therapy use in andrology, which calls for the engagement of nanotechnology.
\end{abstract}

Keywords: Nanotechnology; nanoparticle; erectile dysfunction (ED); premature ejaculation (PE)

Submitted Dec 25, 2019. Accepted for publication Jan 16, 2020.

doi: $10.21037 /$ tau.2020.01.18

View this article at: http://dx.doi.org/10.21037/tau.2020.01.18

\section{Introduction}

Nanotechnology, benefited from the progression of microphysics that takes insight into materials on atom level, provides us with a new tool to explore the disease mechanism and new treatment strategy and new diagnostic method on nanoscale. It has been the hot point in the field of translational medicine for many years. Nanoparticles are defined as the materials whose scale ranges between 1-1,000 nanometers. With the characteristic of high surface area-to-volume ratio, flexible construction and relative biocompatibility (1), nanoparticle makes it possible to insert therapeutic effect precisely. Erectile dysfunction (ED) and premature ejaculation (PE) are the most common forms of sexual dysfunction for males. It was reported $9-29 \%$ men were bothered with alteration in sexual function (2). At least $20 \%$ of men had the experience of PE (3) and, among men aging between 40 and 70 years old, the occurrence rate of ED could be as high as $52 \%$ (4). However, the current available therapeutic option for ED and PE have not been updated for years, which include oral phosphodiesterase-5 (PDE-5) inhibitors, intracavernosal injection therapy, extracorporeal shock wave therapy (ESWT), vacuum constriction devices, penile prothesis transplant for ED and selective serotonin reuptake inhibitor (SSRI), serotonin-norepinephrine reuptake inhibitor (SNRI) for PE. Almost all of the current therapies have some obvious shortcomings, concerning the effectiveness, safety and side effects, making it far beyond satisfactory for patients. In this review, nanotechnology associated novel treatment including drug delivery, gene therapy and stem therapy for ED and PE were summarized as to their limitation and advantages.

\section{Drug delivery}

PDE-5 is including tadalafil, sialorphin, avanafil are widely used in patients with ED for its ability of competitively binding and inhibiting PDE-5 isoenzyme. All of the current used PDE-5 are administered in oral approach for 
their poor aqueous solubility, which could result in low bioavailability and systemic side effects like facial flushing, headache, nasal congestion and dyspepsia (5) and need to be noted before prescription. As one of the most commonly used pharmacy for PE, dapoxetine, a kind of SSRIs, could reach a peak of serum concentration in a short period (after $\sim 1.25 \mathrm{~h}$ ) and the elimination half-time is about $1.31 \mathrm{~h} \mathrm{(6).}$ However, because of the existence of hepatic first pass metabolism, the bioavailability of oral administered dapoxetine could be as low as $42 \%$ (7).

With the application of nanotechnology, new approaches of medicine delivery were explored to promote the efficacy and minimize the side effects of current available agents.

\section{Nanoparticle based transdermal delivery system}

Solid lipid nanoparticles (SLNs), first developed in 1990s for oral administration (8), are characterized by their submicron size. This kind of nanocarrier-based delivery system is composed of a lipid solid matrix stabilized by a surfactant (9). In the drug delivery system based on SLNs, lipid matrix crystal voids encapsulated agents were exempted from degradation in the process of delivery and prolonged release in the targeted area was observed (10). Obvious advantages over traditional drug delivery is expected in SLNs based transdermal delivery system as it could release at the certain site, thus minimizing the side effects that could be caused by oral administration. It is theoretically safe to apply this kind of materials on skin for its phospholipids substance, which are non-toxic and non-irritant. In addition, significant decreased total transepidermal water loss and increased surface area in this nanoparticle conjugated delivery system enables longer residence and contact of drugs (11). Kurakula et al. in their study evaluated the permeation parameters and release mechanism of avanafil SLN in rat model (10). In this study, it was observed that the penetrating ability of avanafil was enhanced by SLNs, suggesting that SLNs could be an effective approach for transdermal drug delivery.

In another study, Han et al. explored the effectiveness of erectogenic agents including tadalafil, sialorphin, and nitric oxide $(\mathrm{NO})$ in ED treatment when encapsulated by nanoparticles (12). A kind of nanoparticle based hybrid hydrogel/glass was used as the delivery system in this study. Systemic blood pressure (BP) and intracorporal pressure (ICP) were measured and continuously monitored throughout the experiment.

In the group treated with nanoparticles encapsulated
NO, initially spontaneous erection could be observed 4.5 minutes after drug, with a duration of erectile of 1.42 minutes and ICP/BP of $0.67 \pm 0.14$. In sialorphin nanoparticles group, there were 4.5 minutes, 8 minutes and $0.72 \pm 0.13$ respectively, which were significantly different from the empty nanoparticles group. Finally, there yielded a conclusion that the topical erectogenic agents encapsulated by nanoparticle based hybrid hydrogel/glass delivery system could be useful in treating ED when applied to the penis.

Prostaglandin E1 ethyl ester was once reported being applied in a patient with systemic scleroderma. When applied with a transdermal system, a marked increase in blood flow velocity was observed (13). Nanoparticle based delivery system of alcohol hydrogels containing prostaglandin E1 ethyl ester was explored on cat model, in which the alcoholic hydrogel was used as a gel to the penis. ICP was measured to evaluate the effect of this transdermal therapy and the results indicated this delivery system might be effective as an ED treatment alternative (14).

Various liposomal nanoparticulate carriers have been put into clinical use, especially in transdermal therapy as a novel drug delivery system encapsulating those agents with poor solubility, low stability in water and poor permeability of stratum corneum (15). Liposomal nanoparticulate carriers could be subtyped into conventional liposomes (L-RSV), deformable liposomes (LD-RSV), ultradeformable liposomes (LUD-RSV) and ethosomes (Etho-RSV). Ethosomes were evaluated as vardenafil carrier in vitro for ED treatment. Rat model was used and the effects of lipid composition, sonication time, and ethanol concentration on particle size and encapsulation efficiency were evaluated in this study (16). Confocal laser scanning microscopy imaging technique was utilized to measure the diffusion release rate of vardenafil. A supporting result showed that the bioavailability of vardenafil delivered from transdermal pathway in nanoethosome form was approximately twofold higher than that from an oral administered aqueous suspension (16).

\section{Nanoparticle based oral delivery system}

Sildenafil is a widely used PDE-5 inhibitors for treatment of ED, which is insoluble in water. As concerned the insolubility of commercially available sildenafil tablet and the existence of intestinal and hepatic first-pass metabolism ( $80 \%$ of administered oral dose) (17), the effect of sildenafil was impeded for its low oral bioavailability of the tablet (40\%) and delayed onset (45 $\mathrm{min}$ ) and short duration 
of action, with a very short physiological half-life of $4 \mathrm{~h}$ (18). Despite of the modality of nanoparticle based transdermal delivery system, nanoparticle encapsulated sildenafil for oral delivery was also explored. SLNs was used as the carrier for oral sildenafil administration in a study conducted by Hosny et al. (19). Compared to the commercially available sildenafil tablet, this in vivo pharmacokinetic study revealed the SLNs encapsulated sildenafil with enhanced bioavailability by $>1.87$ fold, and the mean residence time was longer (19).

\section{Nanoparticle based intranasal delivery system}

Intranasal drug delivery system was most commonly used in local treatment for diseases like cold, cough and rhinitis. Compared to oral drug administration approach, intranasal approach exhibits characteristics of rapid onset of action, and, as the result of avoidance of first pass metabolism, higher bioavailability $(20,21)$. However, because of the existence of nasal mucosal barrier and nasal enzyme system, it was hard to insert therapy for other organ by intranasal approach. With the utilization of nanoparticle drug delivery system that could enable efficiently transmucosal delivery and protect the agents from enzyme degradation, it has been explored to transport pharmacy into systemic circulation, thus for the treatment for disease in other organs. In the field of andrology, Fouad et al. produced an instantly-dispersible nanocarrier powder system (IDNPs) for intranasal delivery of dapoxetine in their study (22). This nanocarrier system was evaluated for its ex-vivo permeation and in-vivo pharmacokinetic parameters in rabbit model and compared with a corresponding oral nanocarrier administration group. Higher bioavailability $(235.41 \%$ to oral group) was observed in intranasal nanocarrier group, which confirmed that even encapsulated in nanoparticles, agents could not be efficiently absorbed in oral approach due to the existence of hepatic first pass metabolism. Intranasal route, however provide with a new insight into the solution of avoidance of hepatic first pass degradation and increase the bioavailability when joined with the application of nanoparticles. In another study, tadalafil nanoemulsions were delivered in intranasal approach and evaluated for its characterization and pharmacodynamic parameters (23). Tumor necrosis factor-a (TNF-a) and caspase-3 in rat nasal tissues were assessed for nasal toxicity and cyclic guanosine monophosphate (cGMP) in rat penis 2-h post-treatment was assessed for efficacy. No significant difference in values of TNF-a and caspase- 3 between the nanoemulsion treated groups and the control group and a significantly higher level of cGMP in intranasal nanoemulsions group were observed, indicating the intranasal naneomulsion delivery system could be safe and effective in ED treatment.

\section{Gene therapy}

Gene therapy is a promising aspect for ED treatment as it has some prominent advantages over oral therapies. Most of the oral medicines like PDE-5 inhibitors are short lived and need to be taken on-demand, which means the sexual activity need to be planed. Though some studies have explored the treatment of daily low-dose PDE-5 inhibitors and the results are promising $(24,25)$, it requires daily drug taking and the compliance of patients could be unsatisfactory. The effect of gene therapy could last for a relatively long period for the rate of smooth muscle turnover is relatively slow in penis (26), thus making it more acceptable for those patients.

Generally, gene therapy refers to using nucleic acids to treat and control diseases. Viral and non-viral vectors are most used gene carriers for delivering foreign therapeutic genes into somatic cells $(27,28)$. Current gene therapies in ED could be categorized into activators of the nitrergicneural system, endothelial growth factors (GFs) promoters, and modulators of ion channels in smooth muscle cells (26). The knowledge of gene therapy in ED has been expanded with the increasing understanding of the pathophysiological mechanism involved in ED. Molecular targets including nitrous oxide synthase (NOS), neurotrophic and angiogenic factors, potassium channels, prostacyclin I2 synthase (PGIS), antifibrotic factors, and peptides have been well studied in previous studies and most of these studies were conducted on animal models, concerned the safety. The results have been summarized in a recent review by $\mathrm{Yu}$ et al. (29). However, most of the studies discussed used viral vectors for gene transferring, which result in a limitation in human application for safety uncertainty. Virus vector including retrovirus, adenovirus, herpes simplex virus 1 (HSV-1), vaccinia virus, lentivirus, baculo virus, moloney murine leukemia virus (MLV proteins) and adenoassociated virus (30) were once the most widely used vector in conventional gene delivery. Though promising was gene therapy demonstrated in the field of medicine, the progress of viral vector in further clinical application was impeded for its drawback including immunogenicity, cytotoxicity, inflammatory reaction towards viral vectors and insertional mutagenesis of gene delivering viral vectors (31).

The first human trial using non-viral gene carrier for 
gene therapy in ED patients was reported in 2005 (32). In this study, hMaxi-K, a kind of modulator of ion channels in smooth muscle cells was administered intracorporally. They designed a single administration of three escalating doses of hMaxi-K injected into the cavernous body. EKG, general blood electrolyte and liver chemistries, hematologic parameters, sex hormone, cortisol, thyroid profiles, urine and semen analysis was conducted to assess the safety and tolerability of hMaxi-K. Results of the study showed there was no drug related adverse event observed during sixmonth follow-up. Naked DNA was chosen as the gene transfer vector in this study and thus could theoretically reduce the incidence of adverse effects like immune and inflammation, which could be wide common in gene therapy using viral vector.

However, naked DNA is not widely used as the vector in gene therapy for its lack of efficiency in transfer and short duration (33).

Researchers were put into a dilemma in making the gene transferring effective and safe at the same time till the emergence of nanotechnology, which greatly boosted the application of non-viral vector. Nanoparticles, with its diameter ranging from 10 to $200 \mathrm{~nm}$, are born with some eminent properties. As the size of nanoparticles is close to that of protein molecules, it could penetrate the tissue deeply and easily $(34,35)$. On the cellular level, nanoparticles could interact with the biomolecules on the cell surface or inside cell, making it possible for a targeted gene delivery (36). Several delivery tools have been designed based on different nanoparticles, such as magnetic nanoparticles, carbon nanotubes, liposomes and gold nanoparticles $(37,38)$. Though previous studies using viral vectors have demonstrated the effectiveness of gene therapy in ED in animal model, there is no experiment performed using non-viral vector based on nanoparticle, which could be the next step of value to be explored.

\section{Stem cell therapy}

Stem cells, defined as those cells with self-renewal ability and the potency of multi-differentiation, are now widely used in the field of medicine. In recent years, stem cell therapy has been gaining more and more attention for the treatment of ED, especially that are resulted from cavernous nerve $(\mathrm{CN})$ injury. $\mathrm{CN}$ injury induced $\mathrm{ED}$ is common in patients who underwent radical prostatectomy (RP) and the morbidity of RP-induced-ED ranges from $20-93.9 \%$ according to previous study (39-41). The value of stem therapy for ED treatment in animal model has been well studied (42-45). Most of the studies reported a positive effect of stem cell therapy on ED patients. Meanwhile, the mechanism was also studied and the most widely accepted theory could be summarized as: (I) stem cells could promote the regeneration of $\mathrm{CN}$ by secreting GFs in paracrine pathway (46); (II) adipose-derived stem cells (ADSC) repaired the damage of corpus cavernosum to improve erectile function by directly differentiating into cavernous endothelial cells and smooth muscle cells (47); (III) exosomes secreted by ADSC could inhibit the apoptosis of corpus cavernosum endothelial and smooth muscle cells (48); (IV) ADSC act through releasing intracellular preformed substances or by secreting certain biomolecules (49). An important hurdle that impede the clinical application of stem cell therapy in ED is the high blood clearance in penis (50), which could make it difficult for ADSCs to be retained locally. Lin et al., in their study observed ADSCs exited the penis within days of IC injection and migrated preferentially to bone marrow (51). Thus, researchers explored the usage of magnetic nanoparticle to retain the magnetized stem cells in corpus cavernosum so that the stem cells could reside in the target area for a relatively long period.

Lin et al. performed a study to investigate the efficacy of using magnetic nanoparticles to maintain stem cells in the corpus cavernosum after intracavernous injection (ICI) in animal model (52). In this study, bilateral cavernous nerve crush (BCNC) was performed on rats to establish the ED model, which were then randomly assigned into three groups: ADSCs treated group, nano-ADSCs treated group and nanoADSCs + magnet treated group. Cell tracking results showed that under the usage of magnetized nanoparticle, ADSCs could be retained in the corpus cavernosum for up to 3 days, compared to those ADSCs in other groups washed out by day 1 after ICI. The intracavernous pressure (ICP)/mean arterial pressure (MAP) ratio was measured to assess the erectile function and the results showed that the ICP/MAP ratio in $\mathrm{BCNC}+$ nano-ADSCs + magnet group (52.22 \pm 5.36$)$ was significantly higher than in BCNC + nano-ADSCs group (37.06 \pm 3.94$)$. It was concluded in this study that magnetized nanoparticles could be effective in retaining ADSCs locally in corpus cavernosum and promote the effect of stem cell therapy for ED.

In another study reported by Zhu et al. (53), they labeled the ADSCs with superparamagnetic iron oxide nanoparticles (SPIONs) and evaluate its effect in ED treatment in diabetic rat model. In this study, diabetic rats were assigned into 3 groups: phosphate-buffered saline (PBS) treated group, 
ADSCs labeled with SPIONs treated group (ADSC group) and SPION-labeled ADSCs with magnetic field application treated group (M-ADSC group). Study results showed SPION-labeled ADSCs responded to exterior magnetic fields both in vitro and in vivo and the measurement of ICP/MAP ratio showed a significant improvement of erectile function in M-ADSC group compared to ADSC group. A similarly designed study evaluating the efficacy of superparamagnetic iron oxide nanoparticles-labeled human mesenchymal stem cells (SPION-MSCs) for ED treatment by transplanting SPION-MSCs into the CN injured cavernosa of rats was reported by Kim et al. (54). Results showed that SPION-MSCs treated group exhibited better erectile function according to the ICP/MAP ratio and a significant longer existence of transplanted SPIONMSCs for up to 4 weeks was confirmed in SPION-MSCs treated group (54). These findings suggest the application of magnetic nanoparticles bound to ADSCs could be an effective approach in retaining the stem cells in therapeutic target and promote its therapeutic efficacy. Long-term study results on the safety and tolerability of magnetic nanoparticles conjugated stem cell in vivo were needed for further discussion.

\section{Conclusions}

In this review, we take a look into the application of nanotechnology in andrology, especially in the treatment for ED and PE. Traditional treatments like PDE-5 inhibitors, SSRI and newly emerging treatments like gene therapy and stem therapy are all far beyond fantastic therapies for their systemic side effects, risk of immunogenicity, cytotoxicity, inflammatory reaction and lack of targeting. Nanotechnology provides us with a method to ameliorate the situation. It should be addressed that most of the relevant studies were conducted on animal models and there is still a long way to go before bringing it into clinical use, which calls for long-term study results to explore its' safety in vivo.

\section{Acknowledgments}

Funding: None.

\section{Footnote}

Conflicts of Interest: All authors have completed the ICMJE uniform disclosure form (available at http://dx.doi. org/10.21037/tau.2020.01.18). The authors have no conflicts of interest to declare.

Ethical Statement: The authors are accountable for all aspects of the work in ensuring that questions related to the accuracy or integrity of any part of the work are appropriately investigated and resolved.

Open Access Statement: This is an Open Access article distributed in accordance with the Creative Commons Attribution-NonCommercial-NoDerivs 4.0 International License (CC BY-NC-ND 4.0), which permits the noncommercial replication and distribution of the article with the strict proviso that no changes or edits are made and the original work is properly cited (including links to both the formal publication through the relevant DOI and the license). See: https://creativecommons.org/licenses/by-nc$\mathrm{nd} / 4.0 /$.

\section{References}

1. Wang X, Yang L, Chen ZG, et al. Application of nanotechnology in cancer therapy and imaging. CA Cancer J Clin 2008;58:97-110.

2. Laumann EO, Nicolosi A, Glasser DB, et al. Sexual problems among women and men aged 40-80 y: prevalence and correlates identified in the Global Study of Sexual Attitudes and Behaviors. Int J Impot Res 2005;17:39-57.

3. Patrick DL, Althof SE, Pryor JL, et al. Premature ejaculation: an observational study of men and their partners. J Sex Med 2005;2:358-67.

4. Feldman HA, Goldstein I, Hatzichristou DG, et al. Impotence and its medical and psychosocial correlates: results of the Massachusetts Male Aging Study. J Urol 1994;151:54-61.

5. Wang AY, Podlasek CA. Role of nanotechnology in erectile dysfunction treatment. J Sex Med 2017;14:36-43.

6. McMahon CG. Dapoxetine: a new option in the medical management of premature ejaculation. Ther Adv Urol 2012;4:233-51.

7. Andersson KE, Mulhall JP, Wyllie MG. Pharmacokinetic and pharmacodynamic features of dapoxetine, a novel drug for 'on-demand' treatment of premature ejaculation. BJU Int 2006;97:311-5.

8. Müller RH, Radtke M, Wissing SA. Nanostructured lipid matrices for improved microencapsulation of drugs. Int J Pharm 2002;242:121-8.

9. Urbán-Morlán Z, Ganem-Rondero A, Melgoza- 
Contreras LM, et al. Preparation and characterization of solid lipid nanoparticles containing cyclosporine by the emulsification-diffusion method. Int J Nanomedicine. 2010;5:611-20.

10. Kurakula M, Ahmed OA, Fahmy UA, et al. Solid lipid nanoparticles for transdermal delivery of avanafil: optimization, formulation, in-vitro and ex-vivo studies. J Liposome Res 2016;26:288-96.

11. Jenning V, Schäfer-Korting M, Gohla S. Vitamin A-loaded solid lipid nanoparticles for topical use: drug release properties. J Control Release 2000;66:115-26.

12. Han G, Tar M, Kuppam DS, et al. Nanoparticles as a novel delivery vehicle for therapeutics targeting erectile dysfunction. J Sex Med 2010;7:224-33.

13. Schlez A, Kittel M, Scheurle B, et al. Transdermal application of prostaglandin E1 ethyl ester for the treatment of trophic acral skin lesions in a patient with systemic scleroderma. J Eur Acad Dermatol Venereol 2002;16:526-8.

14. Park HS, Yang SW, Choi SU, et al. In vitro skin penetration and pharmacodynamic evaluation of prostaglandin E1 ethyl ester, a vasoactive prodrug of prostaglandin E1, formulated into alcoholic hydrogels. Pharmazie 2006;61:933-7.

15. Tosato MG, Maya Girón JV, Martin AA, et al. Comparative study of transdermal drug delivery systems of resveratrol: high efficiency of deformable liposomes. Mater Sci Eng C Mater Biol Appl 2018;90:356-64.

16. Fahmy UA. Nanoethosomal transdermal delivery of vardenafil for treatment of erectile dysfunction: optimization, characterization, and in vivo evaluation. Drug Des Devel Ther 2015;9:6129-37.

17. Shin HS, Bae SK, Lee MG. Pharmacokinetics of sildenafil after intravenous and oral administration in rats: hepatic and intestinal first-pass effects. Int J Pharm 2006;320:64-70.

18. Fraisse A, Butrous $\mathrm{G}$, Taylor MB, et al. Intravenous sildenafil for postoperative pulmonary hypertension in children with congenital heart disease. Intensive Care Med 2011;37:502-9.

19. Hosny KM, Aljaeid BM. Sildenafil citrate as oral solid lipid nanoparticles: a novel formula with higher bioavailability and sustained action for treatment of erectile dysfunction. Expert Opin Drug Deliv 2014;11:1015-22.

20. Huh Y, Cho HJ, Yoon IS, et al. Preparation and evaluation of spray-dried hyaluronic acid microspheres for intranasal delivery of fexofenadine hydrochloride. Eur J Pharm Sci 2010;40:9-15.
21. Piao HM, Balakrishnan P, Cho HJ, et al. Preparation and evaluation of fexofenadine microemulsions for intranasal delivery. Int J Pharm 2010;395:309-16.

22. Fouad SA, Shamma RN, Basalious EB, et al. Novel instantly-dispersible nanocarrier powder system (IDNPs) for intranasal delivery of dapoxetine hydrochloride: invitro optimization, ex-vivo permeation studies, and in-vivo evaluation. Drug Dev Ind Pharm 2018;44:1443-50.

23. Elbardisy B, Galal S, Abdelmonsif DA, et al. Intranasal tadalafil nanoemulsions: formulation, characterization and pharmacodynamic evaluation. Pharm Dev Technol 2019;24:1083-94.

24. Bolat MS, Cinar O, Akdeniz E, et al. Low dose daily versus on-demand high dose tadalafil in diabetic patients with erectile and ejaculatory dysfunction. Int J Impot Res 2018;30:102-7.

25. Wiggins A, Tsambarlis PN, Abdelsayed G, et al. A treatment algorithm for healthy young men with erectile dysfunction. BJU Int 2019;123:173-9.

26. Patel DP, Pastuszak AW, Hotaling JM. Emerging treatments for erectile dysfunction: a review of novel, nonsurgical options. Curr Urol Rep 2019;20:44.

27. Luo D, Saltzman WM. Synthetic DNA delivery systems. Nat Biotechnol 2000;18:33-7.

28. Roy K, Mao HQ, Huang SK, et al. Oral gene delivery with chitosan--DNA nanoparticles generates immunologic protection in a murine model of peanut allergy. Nat Med 1999;5:387-91.

29. Yu B, Wu C, Li T, et al. Advances in gene therapy for erectile dysfunction: promises and challenges. Curr Gene Ther 2018;18:351-65.

30. Kotterman MA, Chalberg TW, Schaffer DV. Viral Vectors for Gene Therapy: Translational and Clinical Outlook. Annu Rev Biomed Eng 2015;17:63-89.

31. Jeevanandam J, Pal K, Danquah MK. Virus-like nanoparticles as a novel delivery tool in gene therapy. Biochimie 2019;157:38-47.

32. Melman A, Bar-Chama N, McCullough A, et al. The first human trial for gene transfer therapy for the treatment of erectile dysfunction: preliminary results. Eur Urol 2005;48:314-8.

33. Verma IM, Somia N. Gene therapy -- promises, problems and prospects. Nature 1997;389:239-42.

34. Park TG, Jeong JH, Kim SW. Current status of polymeric gene delivery systems. Adv Drug Deliv Rev 2006;58:467-86.

35. Pissuwan D, Niidome T, Cortie MB. The forthcoming applications of gold nanoparticles in drug and gene delivery systems. J Control Release 2011;149:65-71. 
36. Kaul G, Amiji M. Tumor-targeted gene delivery using poly(ethylene glycol)-modified gelatin nanoparticles: in vitro and in vivo studies. Pharm Res 2005;22:951-61.

37. Gao L, Nie L, Wang T, et al. Carbon nanotube delivery of the GFP gene into mammalian cells. Chembiochem 2006;7:239-42.

38. Suzuki R, Takizawa T, Negishi Y, et al. Effective gene delivery with novel liposomal bubbles and ultrasonic destruction technology. Int J Pharm 2008;354:49-55.

39. Martínez-Salamanca JI, La Fuente JM, Fernández A, et al. Nitrergic function is lost but endothelial function is preserved in the corpus cavernosum and penile resistance arteries of men after radical prostatectomy. J Sex Med 2015;12:590-9.

40. Resnick MJ, Koyama T, Fan KH, et al. Long-term functional outcomes after treatment for localized prostate cancer. N Engl J Med 2013;368:436-45.

41. Ficarra V, Novara G, Artibani W, et al. Retropubic, laparoscopic, and robot-assisted radical prostatectomy: a systematic review and cumulative analysis of comparative studies. Eur Urol 2009;55:1037-63.

42. Fandel TM, Albersen M, Lin G, et al. Recruitment of intracavernously injected adipose-derived stem cells to the major pelvic ganglion improves erectile function in a rat model of cavernous nerve injury. Eur Urol 2012;61:201-10.

43. Bochinski D, Lin GT, Nunes L, et al. The effect of neural embryonic stem cell therapy in a rat model of cavernosal nerve injury. BJU Int 2004;94:904-9.

44. Castiglione F, Hedlund P, Van der Aa F, et al. Intratunical injection of human adipose tissue-derived stem cells prevents fibrosis and is associated with improved erectile function in a rat model of Peyronie's disease. Eur Urol 2013;63:551-60.

45. Chen X, Yang Q, Zheng T, et al. Neurotrophic effect

Cite this article as: Liu SZ, Feng DC, Liu ZH, Liang JY, Ren ZJ, Zhou C, Wu K, Zhang FX, Zhang F, Lu YP, Wang XD. Development of nanotechnology in andrology. Transl Androl Urol 2020;9(2):702-708. doi: 10.21037/tau.2020.01.18 of adipose tissue-derived stem cells on erectile function recovery by pigment epithelium-derived factor secretion in a rat model of cavernous nerve injury. Stem Cells Int 2016;2016:5161248.

46. Vakalopoulos I, Memmos D, Mykoniatis I, et al. Stem cell therapy in erectile dysfunction: science fiction or realistic treatment option? Hormones (Athens) 2018;17:315-20.

47. Lin G, Banie L, Ning H, et al. Potential of adiposederived stem cells for treatment of erectile dysfunction. J Sex Med 2009;6 Suppl 3:320-7.

48. Chen F, Zhang H, Wang Z, et al. Adipose-derived stem cell-derived exosomes ameliorate erectile dysfunction in a rat model of type 2 diabetes. J Sex Med 2017;14:1084-94.

49. Albersen M, Fandel TM, Lin G, et al. Injections of adipose tissue-derived stem cells and stem cell lysate improve recovery of erectile function in a rat model of cavernous nerve injury. J Sex Med 2010;7:3331-40.

50. Lin CS, Xin ZC, Wang Z, et al. Stem cell therapy for erectile dysfunction: a critical review. Stem Cells Dev 2012;21:343-51.

51. Lin G, Qiu X, Fandel T, et al. Tracking intracavernously injected adipose-derived stem cells to bone marrow. Int J Impot Res 2011;23:268-75.

52. Lin H, Dhanani N, Tseng H, et al. Nanoparticle improved stem cell therapy for erectile dysfunction in a rat model of cavernous nerve injury. J Urol 2016;195:788-95.

53. Zhu LL, Zhang Z, Jiang HS, et al. Superparamagnetic iron oxide nanoparticle targeting of adipose tissue-derived stem cells in diabetes-associated erectile dysfunction. Asian J Androl 2017;19:425-32.

54. Kim JH, Lee HJ, Doo SH, et al. Use of nanoparticles to monitor human mesenchymal stem cells transplanted into penile cavernosum of rats with erectile dysfunction. Korean J Urol 2015;56:280-7. 